\title{
Surgical Experience of No-scalpel Vasectomy: An Underutilized Procedure
}

\author{
Chitra Vashnavi', Anil Gupta ${ }^{2}$, Manmeet Kaur ${ }^{3}$, Raj Rishi Sharma ${ }^{4}$, Ranjeet Rathore ${ }^{3}$ \\ ${ }^{1}$ Medical Suprintendent (MD Community Medicine) Kathua, $J \& K,{ }^{2}$ Consultant, ${ }^{3}$ Assistant Professor Department of \\ Surgery, ${ }^{4}$ Professor Department of Surgery, GMC, Kathua, $J \& K$
}

\begin{abstract}
Introduction: No-Scalpel Vasectomy is a safe and effective technique of male fertility control. It is a minor procedure with minimal side effects and thus increases the patient acceptance, who have a vital role in decision making for family planning. Aims: to present our experience and results in patients undergoing no-scalpel vasectomy, their motivating factors, the failure rate of vasectomy, complications and its effect on sexual desire and performance. Material and Method : A total of 204 patients undergoing a no-scalpel vasectomy between march 2015 and august 2019 were included. Details about their motivational factors, socio-demographic profile were noted and post vasectomy complications were recorded and assesed. Results: No immediate or delayed complications of haematoma, wound infection, scrotal sinus, vasectomy failure, sperm granuloma and chronic scrotal pain was observed. Only one patient presented with pain and stitch granuloma which was excised later. None of our patients presented with any psychological and sexual problems in the follow-up. Conclusions: Men are often reluctant to consider vasectomy because of inaccurate information and myths. No-Scalpel Vasectomy is a safe procedure, but adequate motivation and education about the procedure is a must with follow up and sperm count at 3 months.
\end{abstract}

Key words: Contraceptive, vasectomy, sperm count.

\section{Introduction}

In this modern world responsibility of a male does not end only with fathering of a child, but for prosperity of the family and in the long run for the development of the country they also have a vital role in making decision of family planning. The role of the husbands become more important in a country like India where males mostly are the head of families and principal decision makers. With the population growth rate at $1.58 \%$, India is predicted to have more than 1.53 billion people by the end of $2030^{1}$, and to have a population of 1.4 billion in 2026. To control this population explosion we need availability of family planning services that provide a choices for both permanent and spacing methods. ${ }^{2}$ The no-scalpel vasectomy (NSV) was developed in

\section{Corresponding author:}

\section{Dr. Manmeet Kaur}

H.NO. 6, Apna Vihar, Kunjwani, Jammu-180010.

Phone No. 9958030272

E-mail: drmanmeetkaur79@gmail.com
China by Dr. Li Shunqiang in $1974^{3,4}$ and introduced in India in 1991 by two surgeons, Dr. R.C.M. Kaza and Dr. Alok Banerjee being the pioneers. Officially Non scalpel Vasectomy technique was introduced in India in march 1992 to increase the male participation in family planning methods, but birth control for men in India has barely progressed since its introduction in the year 1992, even though vasectomy is a minor procedure with minimal side effects. Female sterilization is still the most popular method of birth control in India. ${ }^{5}$ Cost-wise also, the ratio is about 5 vasectomies to one tubal ligation. ${ }^{6}$ Vasectomy's advantages over female sterilization include lower rates of postoperative complications, shorter recovery time, lower costs and increased involvement of men in reproductive decisionmaking. ${ }^{7}$

Increased use of temporary male contraceptives has been reported in India, but the use of permanent contraception is very low. So, to overcome all these barriers the Government of India have taken some notable steps to increase the rates of male sterilization. 
An incentive of Rs.1100 is made available to clients/ acceptors after the procedure. In the case of failure, the government gives an amount of Rs.30000/- to the client as compensation. A five days leave is allotted for those employed in the Government sector. Despite of the best of efforts and NSV being a simple and safe method, it has failed to achieve its goal. ${ }^{8}$ This is evident by the fact that the current acceptance of NSV in India has declined from 1 percent (NFHS 3) to 0.3 percent (NFHS 4). Also, there is a magnanimous difference between female and male sterilization in India - 36 percent female as against 0.3 percent male sterilization (NFHS 4). ${ }^{9,10}$ Thus, it is quite evident that no scalpel vasectomy is highly underutilized as a method of male contraception inspite of the fact that tubectomies need costly setup, expensive and cumbersome instruments as in laparoscopic tubal ligations. The major reasons which came up in the studies was the belief among men and women that vasectomy will lead to loss of libido, sexual power and may cause weakness to the men. ${ }^{11,12,13}$ Men are often reluctant to consider vasectomy because of inaccurate information and myths. Vasectomy does not affect production of male hormones that control the sex drive, erection, or masculine features, such as facial hair or muscle tone. The method simply prevents sperm from being in the ejaculate. ${ }^{11}$ Aim of study was to present our experience and results in patients undergoing a noscalpel vasectomy, their motivating factors, the failure rate of vasectomy, complications and its effect on sexual desire and performance.

\section{Material and Method}

A total of 204 patients undergoing a no-scalpel vasectomy and follow-up between march 2015 and august 2019 were included. With prior counselling by field health workers, we again counselled the patients in camps together to remove any apprehensions. Any client who still had apprehensions and clients with allergy to local anaesthesia, genito-urinary or groin infections were excluded. An informed written consent on prescribed format was taken. The cases were done in rural hospitals \& Primary health centres as camp procedure and in district hospital associated with GMC Kathua. Details about their motivational factors to adopt this method of contraception along with other desired socio-demographic details were noted( table 1 and 2). Procedure was performed under local anaesthesia using specially designed vas fixing forceps(ringed clamp). Steps followed include
1. The "three finger grasp"

2. Grasping the vas with vas ring clamp. (fig.1)

3. Piercing skin with vas dissector ( curved sharp pointed haemostat fig. 1)

4. Spreading skin and fascia

5. Hooking the vas(fig. 2)

6. Pulling vas out

7. Grasping it with vas ring clamp

8. Cleaning fascia from vas with vas dissector.(fig.3)

Vas is then occluded both at prostatic and testicular end seperately, about $1 \mathrm{~cm}$ of vas segment is excised as in conventional vasectomy. Prostatic end is pulled and covered with fascial sheath and both ends allowed to slip back into scrotum, small antiseptic dressing done. After having gone through the procedure each of acceptors was asked to come for follow-up after 3days, 15days and 3months. At each follow-up visit complications if any was observed, noted and treated. At the time of last follow-up semen examination was also carried out.

Data thus collected was compiled, classified and analyzed to draw inferences. Following the procedure, clients were advised to take rest for $24 \mathrm{~h}$, avoid cycling for 7 days, wear tight underwears for $48 \mathrm{~h}$, use temporary contraceptive methods by either of the partners for 3 months or at least for 20 ejaculations, and after the report for analysis of semen after 3 months, the certificate was issued.

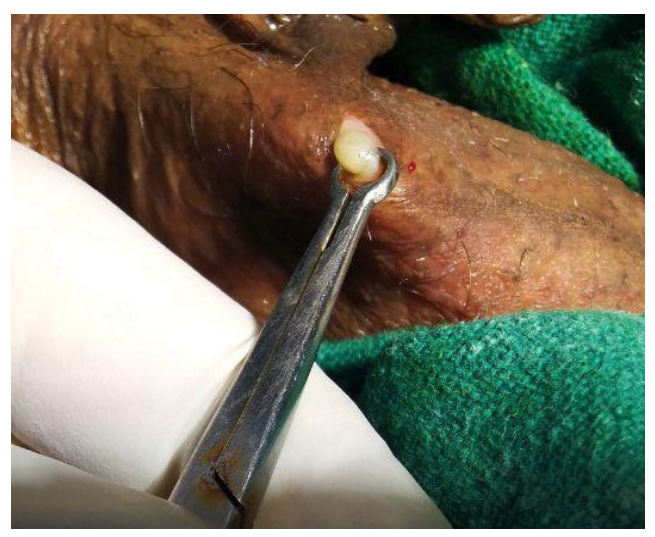




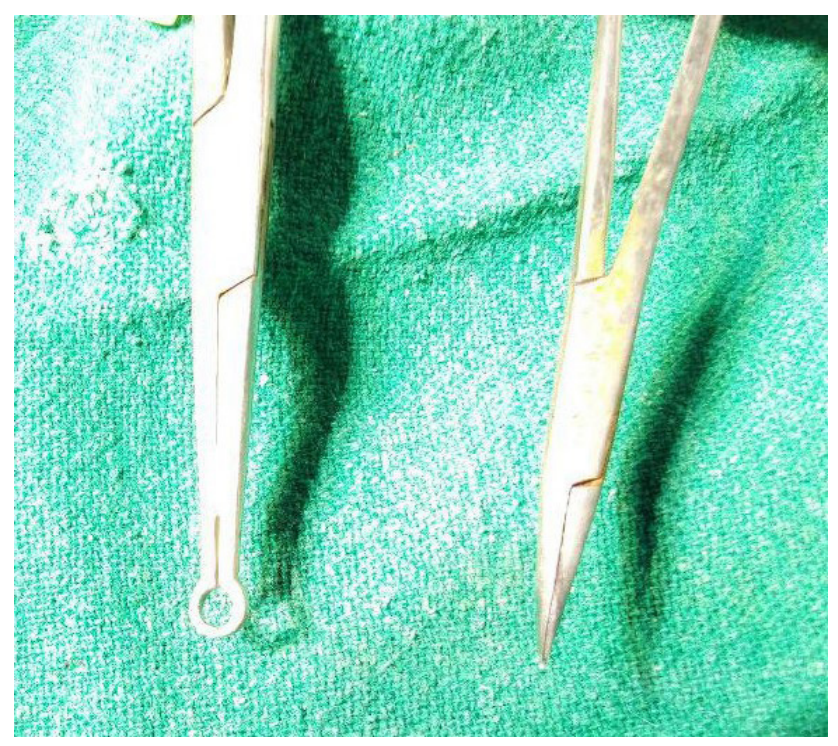

Fig. 1- curved vas dissector and ring clamp Fig. 2- Vas hooking

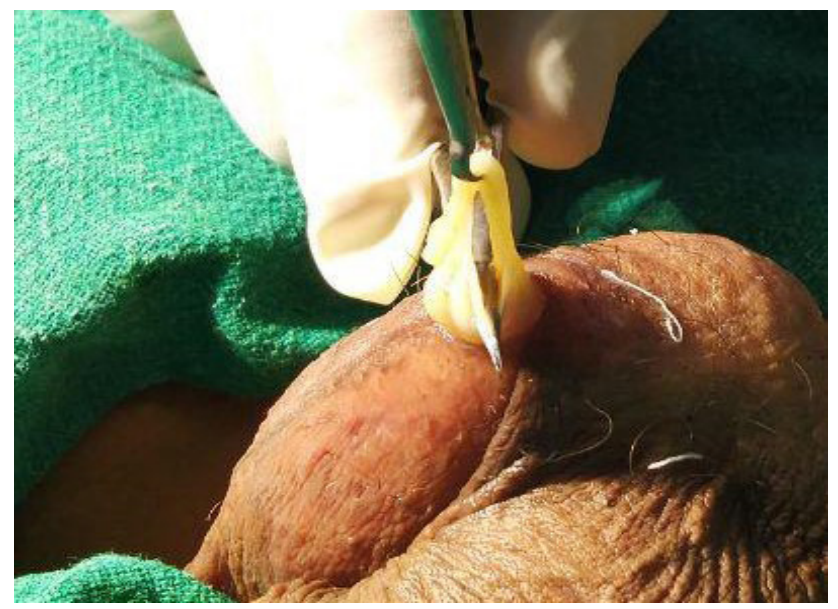

Fig. 3- Cleaning fascia from vas

TABLE I. Socio-demographic characteristics $(n=204)$

\begin{tabular}{|l|l|l|}
\hline Age (years) & no. of acceptors & \%age \\
\hline $20-25$ & 8 & $3.9 \%$ \\
\hline $26-30$ & 43 & $21.1 \%$ \\
\hline $31-35$ & 69 & $33.8 \%$ \\
\hline $36-40$ & 49 & $24 \%$ \\
\hline $41-45$ & 25 & $12.3 \%$ \\
\hline $46-50$ & 10 & $4.9 \%$ \\
\hline Religion & no. of acceptors & $\%$ age \\
\hline Hindu & 183 & $89.7 \%$ \\
\hline Any other & 21 & $10.3 \%$ \\
\hline no. of children & no. of acceptors & $\%$ age \\
\hline 1 & 3 & $1.5 \%$ \\
\hline 2 & 79 & $38.7 \%$ \\
\hline
\end{tabular}

\begin{tabular}{|l|l|l|}
\hline 3 or $>3$ & 122 & $59.8 \%$ \\
\hline $\begin{array}{l}\text { Information } \\
\text { Sources }\end{array}$ & no. of acceptors & $\%$ age \\
\hline $\begin{array}{l}\text { Family Planning } \\
\text { Clinic }\end{array}$ & 107 & $52.5 \%$ \\
\hline $\begin{array}{l}\text { Radio and } \\
\text { Television }\end{array}$ & 72 & $35.3 \%$ \\
\hline Friends & 15 & $7.3 \%$ \\
\hline $\begin{array}{l}\text { Printed } \\
\text { advertisements }\end{array}$ & 10 & $4.9 \%$ \\
\hline
\end{tabular}

Maximum clients were in the age group of 31-40 years(118). Since the region is a Hindu dominated area so maximum clients belonged to Hindu religion only. Our family planning clinics played the major role in motivating the patients to adopt the method in our study. No immediate or delayed complications of haematoma, wound infection, scrotal sinus, vasectomy failure, sperm granuloma and chronic scrotal pain were observed. Only one patient presented with pain and stitch granuloma which was excised later on(fig.4) and he improved. Not even a single failure was reported in our study, 91.2\%(186) of our patients were azoospermic after 3 months and 100\% at end of 4 months. None of our patients presented with any psychological and sexual problems in the follow-up.

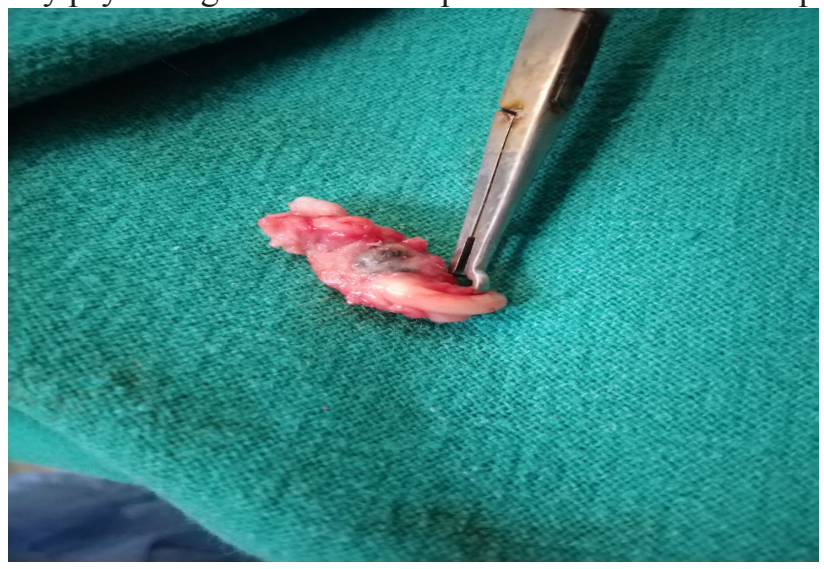

Fig.4-stitch granuloma 
Table 2: Motivating Factors for Adopting Vasectomy

\begin{tabular}{|l|l|l|}
\hline Reason Mentioned & $\begin{array}{l}\text { no. of } \\
\text { acceptors }\end{array}$ & \% of Total \\
\hline $\begin{array}{l}\text { Financial (affordibility for } \\
\text { more children) }\end{array}$ & 44 & $21.6 \%$ \\
\hline $\begin{array}{l}\text { Guaranteed welfare } \\
\text { of family } \\
\text { (food, education and } \\
\text { economy) }\end{array}$ & 65 & $31.9 \%$ \\
\hline $\begin{array}{l}\text { Relieve women's burden of } \\
\text { contraceptives }\end{array}$ & 59 & $28.9 \%$ \\
\hline Permanent method & 15 & $7.3 \%$ \\
\hline No side effects & 10 & $5.4 \%$ \\
\hline \begin{tabular}{l} 
Inspiration from satisfied clients \\
\hline
\end{tabular} & $15 \%$ \\
\hline
\end{tabular}

\section{Discussion}

No Scalpel Vasectomy has long been a safe, effective, easy-to-perform method of contraception for men, but require easy access and confidential services.

A client satisfied with vasectomy may prove instrumental in convincing other persons to opt for vasectomy. This has been very aptly narrated by Dr. R.C.M. Kaza, NSV master trainer to the government of India as follows:"NSV is as much an IEC (Information Education Communication) operation as a surgical operation". ${ }^{14}$ The IEC activities must deal with their apprehensions and should assure that most failures can be controlled by proper follow-up and instructions to the man undergoing the procedure. ${ }^{14}$ In our study family planning clinics played the major role in motivating the patients to adopt the method. Men need to understand that they will not be infertile immediately. Inaccurate knowledge often fueled erroneous assumptions about how vasectomy affects men physiologically and psychologically. ${ }^{15,16}$ A Indian study found that women preferred female sterilization over vasectomy because they felt it was better for a woman to be "debilitated" since the economic contributions of men were more highly valued than those of women. ${ }^{16}$ Motivations leading to vasectomy uptake included the desire to limit births, limited financial resources, concern for women's health (desire to avoid pregnancies and contraceptive side effects), and dissatisfaction with other contraceptive methods ${ }^{15,17,18}$ which is also observed in our study. Definitions of 'failure' vary between studies, some defined it as the presence of sperm in the ejaculate 4 months or 20 ejaculations after vasectomy. Studies found that approximately $95 \%$ of men will be azoospermic 4 months post-vasectomy or after approximately 23 ejaculations. ${ }^{19}$ Late failure occurs when motile spermatozoa reappear in ejaculate after proof of success of vasectomy, signifying that recanalisation has occurred which after first year is indeed uncommon; its real frequency is unknown. ${ }^{20}$ Pregnancy in the partner of a vasectomised man is defined as a failure. Association of Reproductive Health Professionals reported failure rate of vasectomy to be only 0.15 percent. ${ }^{21}$ In a systematic review of 56 studies, the time to achieve azoospermia varied, although the median incidence of azoospermia was more than $80 \%$ after 3 months and 20 ejaculations. ${ }^{22}$ $91.2 \%$ of our patients were azoospermic after 3 months and $100 \%$ at end of 4 months and no failure was seen in our study. Labrecque et al. assessed 309 vasectomised men who had a first semen analysis showing motile sperm; by just repeating the semen analysis a delayed vasectomy success could be demonstrated in more than half of them. ${ }^{23}$ The reported overall incidence of sexual and psychological problems after vasectomy varies between 1 and 3\%. ${ }^{24}$ Our results failed to show any effect of vasectomy on our patient's sexual function. Vasectomy is a reliable form of contraception, but patient compliance is must, just providing written instructions about postvasectomy follow-up is not sufficient to achieve a good patient compliance. In our experience we counselled the patients in camps together to remove any apprehensions and semen analysis in follow up was emphasised It is crucial to evaluate the vasectomy candidate with regard to his knowledge of risks and benefits of the procedure, and follow-up schedule and his motivation to proceed with the procedure. Compliance is low if the procedure is imposed by the clinician or partner. Inquiring about the existence of sexual dysfunction prior to vasectomy will help the patient to discuss his problems and will avoid that the procedure be wrongfully blamed to have caused sexual dysfunction..$^{25}$ Choe and Kirkemo identified chronic scrotal pain in $18.7 \%$ of patients after vasectomy, and it had an adverse effect on their quality of life in $2.2 \%$ of those cases..$^{26}$ The cause of this remains controversial; one leading theory proposes that 
the obstruction and resulting dilatation of the epididymal duct produces interstitial fibrosis along with perineural fibrosis and inflammation after the rupture of epididymal ducts, with extravasation of spermatozoa around the epididymal tubules and at the site of vasal transection. Chronic testicular or scrotal pain is a recognized complication of vasectomy, but the exact incidence of such pain remains unknown. McMahon et al reported chronic testicular pain in 33\% of men who had undergone vasectomy, troublesome in $15 \%$ and caused $5 \%$ to seek medical attention. In our study no case of chronic scrotal pain was recorded. ${ }^{27}$

While vasectomy is a highly effective method, failures may occur due to recanalization of the Vas, surgical errors, anatomical variations or failure of contraception during the postoperative waiting period to azoospermia. ${ }^{28}$ Contraindications to vasectomy include scrotal pathology, haematoma, allergy to local anaesthesia, genito-urinary or groin infections and sperm granulomas..$^{29,30}$

\section{Conclusion}

Authors are of the view that No-Scalpel Vasectomy is a safe but adequate motivation and education about the procedure is must. Our efforts should be directed more towards removing their fears and existing information gap than just popularizing the procedure. A client satisfied with vasectomy and field health workers are instrumental in convincing the potential acceptors to opt for vasectomy.

Acknowledgement- We are highly thankful to Dr. Rajnish, for his field work and professional support for conduction of this study. Without his help it would not have been possible to give shape to our work.

\section{Funding: None}

\section{Conflict of Interest: None}

Ethical approval: Yes

\section{References}

1. Mamanshetty SV. Growth of population impact on environmental degradation: an over view of India. Elixir Agriculture. 2012;51:10877-80.

2. Family Welfare Statistics in India, 2011, Statistics Division, Ministry of Health and Family Welfare, Government of India, 2011.
3. Li S Q, Goldstein M, Zhu J, Huber D: The No Scalpel Vasectomy, J Urol, 1991; 145(2):341-344.

4. Bhuyan K, Ali I, Barua SJ. Role of No Scalpel Vasectomy in Male Sterilization. 2012;74(4):284-7.

5. Kumar V, Kaza RM, Singh I, Singhal S, Kumaran V. An evaluation of the no-scalpel vasectomy technique. BJU Int. 1999;83(3):283-4.

6. Rastogi A. Claiming Dignity: Reproductive Rights \& the Law. Human Rights Law Network (HRLN); 2009. Available at https://hrln.org/claimingdignity-reproductive-rights-the-law-2/ Accessed 11 January2018.

7. Vernon R, Solórzano J, Muñoz B. Introducing sustainable vasectomy services in Guatemala. International Family Planning Perspectives. 2007;33(4):182-187.

8. "Vasectomy Fortnight - Information for General Public: On NSV Services. Department of Health and Family Welfare, Government of Delhi; 2017. Available at http://delhi.gov.in/wps/wcm/connect/ doit_health/Health/Home/Family+Welfare/ Family+Planning.html Accessed 23 September 2017.

9. International Institute for Population Sciences (IIPS), ICF. National Family Health Survey (NFHS4), 2015-16: India. Mumbai, 2017.

10. Kishore A, Pan T, Naskar NN. Study on knowledge and practice regarding no scalpel vasectomy (NSV) among male members of eligible couples in a rural community of West Bengal, India. Int J Reprod Contracept ObstetGynecol 2018;7:3294-8.

11. Escobar MC. An exploratory study on service providers' attitude towards vasectomy: Profamilia Clinics, Colombia. In: Escobar MC, eds. AVS. Bogota: AVS International; 1996.

12. Landrey E, Ward V. Perspectives from couples on the vasectomy decision: a six-country study. Reprod Health Matters. 1997;Special issue:58-67.

13. Zafer et al. Study of vasectomy adopters with special reference to motivational factors. Int J Sci Res Publications. 2013 Sep;3(9):1-6.

14. Frajzyngier V, Bunce A, et al. Factors affecting Vasectomy acceptability in the Kigoma region of Tanzania. In: Frajzyngier V, Bunce A, eds. The Acquire Project. E \& R Study No. 5. New York:USAID-Acquire Evaluation and Research Studies June; 2006: 1-28. 
15. Bunce A, Guest G, Searing H, Frajzyngier V, Riwa $P$, Kanama $J$, et al. Factors affecting vasectomy acceptability in Tanzania. Int Fam Plan Perspect. 2007;33(1):13-21.

16. Hall MA, Stephenson RB, Juvekar S. Social and logistical barriers to the use of reversible contraception among women in a rural Indian village. J Health Popul Nutr. 2008;26(2):241-250.

17. Shattuck D, Wesson J, Nsengiyumva $T$, et al. Who chooses vasectomy in Rwanda? Survey data from couples who chose vasectomy, 2010-2012. Contraception. 2014;89(6):564-571.

18. Nian C, Xiaozhang L, Xiaofang P, Qing Y, Minxiang L. Factors influencing the declining trend of vasectomy in Sichuan, China. Southeast Asian J Trop Med Public Health. 2010;41(4):1008-1020.

19. Schwingl PJ, Guess HA. Safety and effectiveness of vasectomy. Fertil Steril 2000;73:923-36.

20. Haldar N, Cranston D, Turner E, et al. How reliable is a vasectomy? Long term follow-up of vasectomised men. Lancet 2000;356:43-4.

21. Association of Reproductive Health Professionals Choosing a birth control method. Failure rate tables. ARHP. 2011:79.Available athttp://www. arhp.org/uploadDocs/choosingqrg.pdf Accessed 18 September 2017.

22. Griffin T, Tooher R, Nowakowski K, et al. How little is enough? The evidence for postvasectomy testing. J Urol 2006;174:29-36.

23. Labrecque M, St-Hilaire K, Turcot L. Delayed vasectomy success in men with a first postvasectomy semen analysis showing motile sperm. Fertil Steril 2005;83:1435-41.

24. Buchholz NP, Weuste R, Mattarelli G, et al. Postvasectomy erectile dysfunction. J Psychosom Res 1994;38:759-62.

25. Manhoso FR, Hoga LA.Men'sexperiencesofvasectomy in the Brazilian Public Health Service. Int Nurs Rev 2005;52:101-8.

26. Choe JM, Kirkemo AK. Questionnaire-based outcomes study of nononcological post-vasectomy complications. J Urol 1996;155:1284-6.

27. McMahon AJ, Buckley J, Taylor A, Lloyd SN, Deane RF, Kirk D. Chronic testicular pain following vasectomy. Br J Urol 1992; 69:188-91

28. Sokal DC. Recent research on vasectomy techniques. Asian J Androl 2003; 5(3):227-230.

29. Lipshultz LI, Banson GS. Vasectomy: an anatomical, physiological and surgical review. In: Cunningham GR, Schill GR, Hafez ESE, editors. Regulation of male fertility. Hague: Martinus Nijhoff ; 1980. p 159-86.

30. Silber SJ. Vasectomy. In: Knobil E, Neill JD, editors. Encyclopedia of reproduction. California: Academic Press; 1998. p 977-85. 